\title{
5. Adolf Remane: Notes on his work on primates
}

\author{
Prof Ulrich Welsch
}

I met Colin Groves for the first time in the Anthropological Institute of the University of Zürich in 1964, where I did some of my PhD thesis research under the supervision of Professor Adolf Remane (1898-1976). The conversations I had with Colin were based on our common enthusiasm for morphology, comparative anatomy, phylogeny and theoretical ideas about the 'natural system', as I called it, following Professor Remane. Key elements of the natural system are the terms homology and analogy, which enabled scientists, even before the time of Charles Darwin, to establish the natural relationships among organisms. This concept was followed up much later with phylogenetic research. Based on my dealings with both scholars, I am convinced that there is a deep similarity between the minds of Adolf Remane and Colin Groves. Both were/are exceptionally gifted morphologists and both authored numerous high quality publications including entire books. In addition, primates were/are the main target of their interests. On a more personal note, to me both were/are very modest, yet at the same time show a sympathetic and friendly self-confidence, without a dogmatic attitude. Both scholars also worked/work with reliable and never failing consistancy, diligence and concentration, in a harmonious way that included uniting fieldwork with theory. They were/are also deeply interested in the historical dimensions of present-day concepts and had/have acquired a truly unusual knowledge in this field. Remane frequently read original texts (e.g. of Aristotle, Goethe and Cuvier), which is also the case of Colin whose own works are based in the classic texts of Buffon and many European authors of the nineteenth century. Both enjoyed/enjoy to share their knowledge freely with students and colleagues and in doing so they often showed/show a good sense of humour. Finally, both were/are outstanding university-academics, with a search for truth guiding their way of thinking.

Of course there are also differences of opinion between the two men. Remane condensed his experience and concepts in the book Foundations of the Natural System, Comparative Anatomy and Phylogenetics in 1952. I am sure that Colin Groves does not agree with every sentence in that book, but I am also sure that he has an understanding for Remane's arguments and logic. While Remane's interest in the scientific theory of taxonomy did not run very deep, I feel sure that he would have wholeheartedly joined in any discussion on Colin's Primate Taxonomy (2001) and that he would have followed in all probability Colin's 'Putting Primate Taxonomy into Practice' even if - deeply in his heart - he may have had reservations in one or the other case. The rest of this chapter will focus 
on the works of Robert Gustav Adolf Remane, which were published in German, thus underappreciated and largely unknown amongst many primatologists. As Colin himself is able to translate German works into English, it is fitting not only because the two men are so similar, but because Colin would appreciate the way that Remane's work was held back by the language in which it was written.

As alluded to above, Professor Robert Gustav Adolf Remane (1898-1976) was a multifaceted and stimulating zoologist. During his career he created a tremendous amount of scientific work including more than 300 publications ranging from unsurpassed monographs on single invertebrate groups (e.g. rotifers), to a broader field of marine biological and ecological topics, to more theoretical work on the foundations of the natural system, comparative anatomy and phylogeny and on practical and theoretical reflections on the phenomenon of homology. One important aspect in this coherent mosaic is Remane's primatological studies which dominated two periods of his career, the first at the beginning (19211928) and the second towards the end (1951-1965). His publications in this field concerned mainly the functional morphology of teeth and dentition of almost all extant and many extinct primate species and the methodological problems of hominoid phylogeny and theoretical problems of primate systematics.

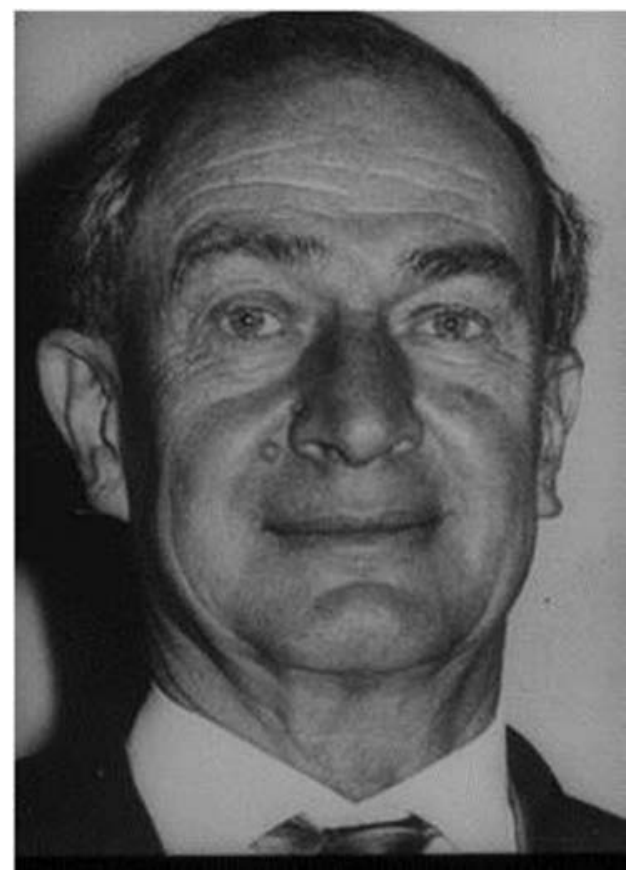

Figure 5.1: Photograph of Professor Remane, at the age of 65.

Source: Given to author as a private gift from the Institute of Zoology in 1967. Photo was taken by the Institute in 1962. 
It was the striking diversity of opinions on fossil teeth, which led him in 1921 to conduct his first thorough study of more than 900 dentition specimens of extant gibbons and apes. Apart from valuable, careful and very detailed descriptions, his work is always marked by a specific sober spirit, guided by an immense knowledge, and by enlightening comparative statements which always create a pleasant intellectual feeling while reading all his papers and articles, not unlike reading one of Colin's papers. He had a gift to not feel compelled to give all problems definitive answers, but was content to ask further questions based on preliminary conclusions. He found particular pleasure in finding the complexity of situations, for example of the possibility of reversibility of phylogenetic trends, of the simultaneous presence of very advanced specialisations and of primitive characters in one animal species (e.g. in Tarsius or in Alouatta).

Reading Remane's texts you always have the impression that you are not wasting your time with boring dental details but that you have gained new general biological insights, both on single primate species and on the interrelationships among primates. For example, in one instance he was able to compare the molar patterns of Apidium, Oreopithecus, Pongo and of human milk molars with interesting results in just a few sentences. The vividness of his thoughts was even more present when he spoke in the lecture hall. In his lectures, the wealth of his knowledge made it easy for him to reflect meaningfully on a variety of topics. He could easily discuss the specific morphological details of human canines or discuss topics considered by Georges Cuvier or Goethe, who on this or that subject had objected to Cuvier's viewpoint, then adding a sentence in ancient Greek, that this or that ambiguity had already been touched by Aristotle, all this quite naturally and without any pretentious attitude. One has to know that he was at home in the entire world of arts, philosophy and natural science in order to understand certain lines of argument in his work. In discussions he was unbeatable, logically thinking with an immense knowledge of all fields of zoology, anthropology, ecology, botany and philosophy, possibly only being rivalled by Colin himself. All his profound primatological - and other - work is free of any personal vanity and is marked by a rare solidity; it was created under often difficult circumstances which were caused by the absurd ups and downs of Central European history in the twentieth century and sometimes by strong personal discomfort due to migraines.

In order to understand Remane's complex theoretical work on the natural system, comparative anatomy and phylogenetics in depth, it is important to be familiar with the, in-part, pre-Darwinian developments of comparative anatomy, mainly in France, England and Germany. Georges Cuvier (1769-1832), Johann Wolfgang Goethe (1749-1832) and Carl Gegenbaur (1826-1903) were constants of orientation. For Cuvier he had a lifelong sympathy. In his lectures, which I had the privilege to hear from 1961-66, he additionally often referred to 
Richard Owen (1804-1892), Etienne Geoffroy Saint-Hilaire (1772-1844), Ernst Haeckel (1834-1919) and William King Gregory (1876-1970), AS Romer (18941832) and to GG Simpson (1902-1984). Of course, he was fully aware of the unique significance of Charles Darwin (1809-1882) for the entire development of modern biology, but now and then slight 'mental reservations' became visible, especially against dogmatic followers of Darwin and those who claimed to be in the possession of 'the' Darwinian truth. Remane knew, that particularly eager protagonists could be good specialists, but could at the same time lack in depth of insight into the entire kingdom of organisms with its endless diversity, and contradictions. He was quite against absolute statements and also saw opaque spots in the 'synthetic evolutionary theory', which ideologically minded debaters did not want to see. The unobtrusive, ever present reference to the scientists of the past was not only an expression of personal modesty but was also of great educational significance for his students. Remane never saw natural science as an anti-thesis to other fields of the human mind such as art, philosophy or religion.

He had a unique gift to analyse and understand morphology, and he was openminded to theoretical questions, but he could also become silent in view of the endless complexity of life. He was also an enthusiastic outdoor biologist with unbeatable knowledge of plants and animals, again similar to Colin's knowledge of most things flora and fauna.

His primatological work was based on the knowledge of several thousand teeth, which he studied personally in all important European museum collections and by careful and serious reading of all relevant literature. Gifted by an obviously inborn feeling for morphology, supported by a unique power of memory and guided by an unusual intelligence, he wrote more than 30 publications and handbook articles with primatological contents, including:

1. Individual topics, such as e.g. the unique morphology of the human canines (Remane, 1924a); or the critical discussion of R. Fourtaus' Prohylobates tandyi and Dryopithecus mogharensis (Remane, 1924b); or the interpretation of the dentition of Oreopithecus (Remane, 1952a) in which he showed that the attempt to derive the pattern of human upper molars from those of Oreopithecus and thus placing Oreopithecus into the hominids, is theoretically possible but only by help of a transitory form on paper and by using a specific variant of human molars; or the presumable phylogenetic position of Gigantopithecus (Remane, 1953), or the origin of bilophodont molars in Cercopithecidae (Remane, 1951); or aberrant morphologies of teeth and skulls.

2. Critical reviews, including those on primate systematics or the 'natural history' of primates (Remane 1956a, 1956b, 1960a, 1965), which due to their original and critical thoughts, are by no means outdated. 
3. Handbook articles, in particular in the Handbook of Primatology (Primatologia) and comparable articles (Remane 1921a, 1921b, 1952b, 1955), which are not word-rich elaborations but concise intelligent compositions full of facts, accompanied by clear line drawings or photomicrographs. The facts are usually condensed into useful tables, e.g. on measurements and proportions of teeth. Already his first publication (1921) on teeth of gibbons and apes is based on the analysis of the skulls of 322 gorillas, 287 chimpanzees, 160 orangutans and 145 gibbons. Such a rich background renders particular weight on specific papers, for example on the dentition of Oreopithecus (Remane, 1952a) or Australopithecus (Remane, 1952b). This analysis also opened his eyes to the remarkable variability of morphological characters of primate teeth, which for him remained a life-long warning not to make definite statements on single fossil teeth or jaw fragments. He gave many important examples for the variability of skull and mandible shape, for example of Pan, of measurements of teeth and of crown patterns (Remane, 1952a), and he took this fact seriously. However, he analysed also single fossil teeth as far as one can go, but never crossed the borders of serious and objective science. The quantitative and qualitative analyses always comprises crown, roots and alveoli and usually details of maxilla and mandible. Of course most information can be extracted from the dental crown, for example patterns of cusps, crests and furrows, including patterns of attrition (Remane 192lab). He was aware that different scientists use different methods, for example when measuring length and width of teeth, which can make it impossible to compare corresponding data. Therefore he suggested application of the same measuring techniques for primate teeth (Remane, 1927). In his contribution on methodic problems of hominid phylogeny II (Remane, 1954), he discusses not only the variability of all types of teeth in apes and man, but also of many cranial characters. Furthermore he carefully discusses pitfalls when not considering variability, which can lead to wrong simplifications and wrong phylogenetic reconstructions. Finally his discussion on species, subspecies and populations, also in regard of fossil findings, is of significance.

What makes Remane's texts and analyses always interesting and often helpful are his often surprising functional correlations, the comparative aspects and of course the always present phylogenetic background. Unfortunately it became a considerable drawback that Remane published almost exclusively in German. As he himself read with ease and pleasure in a multitude of languages including ancient Greek and Latin, French and English he possibly subconsciously expected a similar versatility in English and French-speaking scientists. This language barrier kept many of his publications unknown and underrepresented, but this is a real tragedy due to the fact that his work:

a) contains an invaluable treasure of facts (e.g. dental measurements and evaluations of crown patterns, illustrated by clear drawings) 
b) opens eyes beyond the facts

c) includes, especially in his 1956, 1960 and 1962 handbook articles, all the older European and North-American literature (1900 until about 1960)

d) helps to avoid repetitive work

e) is written in a relatively simple, grammatically correct German.

What also makes such articles valuable even today is that the data can be used for studies not foreseen when they were compiled; primarily they can be transferred into computers for further mathematical evaluations.

When a character was particularly variable, for example the morphology of upper outer incisors or the molar crown patterns of chimpanzees or the morphology of human milk molars, Remane formed groups by which he tried to give some order to the variability. This, today, could be refined by computer analysis. But, it may be added, Remane always remarked, that the best discriminator for visible morphological characters are the human retina (with its many millions of neurons) and brain. In addition he used to say that although large numbers are important to give weight to statements, statements only make sense when the characters are evaluated and not only counted. In this he followed of course the great French comparative anatomists around 1800 and in the early years of the nineteenth century.

His statements were always sober and clear, e.g. 'fossil material too scanty for final statements', 'a well-founded evaluation can be made only when more fossil material is available', 'the XY-index as used in this study for the evaluation of fossil material is almost without any worth', in regard of the inner cusp of $\mathrm{P}_{3}$ : 'since there are regularly variations in regard of the presence of single structures in meristic organs (here the lower premolars) this question has no great significance', etc.

His analysis (1965) of teeth and the fragments of the mandibles of Gigantopithecus blacki are sober and careful and consider not only details of the Pleistocene strata but, in fairness, also the suggestions of other scientists in regard of the systematic position of this big ape (Remane et al., 1960; Remane, 1960a, 1965). He convincingly excludes Gigantopithecus from any lineage towards Homo, as had been suggested before. He carefully excludes Gigantopithecus from any close relationship with Pongo (and Pan); he describes similarities with Gorilla and overlap of teeth sizes with Gorilla beringei. The similarities with Gorilla are common primitive features. He clearly works out specific characters, for example the high hypsodont crowns and the specific morphology of the lower P3 and lower canines and concludes that Gigantopithecus was a herbivore and represents an own lineage of apes rooting probably in the 'Sivalik-pongids'. 
Interesting and worth considering is his 1965 evaluation of the 'SivalikPongiden' - the fossil remains of apes as found in the Sivalik hills (Remane, 1965). He discusses at length all findings and 'species' as described by Lydekker, Pilgrim, Gregory and Hellman, Lewis, von Koenigswald, Hooijer, and Dehm. He mentions among others that the size of the teeth varies from those of Gorilla (Dryopithecus giganteus) to those of a small Pan. The teeth are generally typical for apes. The 'species' are more similar among each other than among extant apes. Single teeth show rather specific agreements with those of Pongo, for example the P3 of 'Sivapithecus himalayensis' (Pilgrim, 1927). Some of these P3-similarities are also to be found in Indopithecus (Hooijer, 1951). The M2 of Dryopithecus giganteus is marked by a pattern of furrows reminding those of Pongo molars. This and additional observations lead him to speculate that ancestors of Pongo may be present among the Sivalik pongids. These possible ancestors, however, have in general more primitive characters than modern Pongo (clearer defined cusps, bigger M3, more rounded symphysis). However, it would be premature to ascribe all Sivalik apes to Pongo and possible relatives. For example, Dryopithecus pilgrimi has rather narrow incisors as can be seen in Gorilla and Dryopithecus fontani. Individual teeth have a high length-widthindex, as to be seen in Gigantopithecus and the closer relationship of Homo. Such individual evaluations take a large part of this contribution. Remane finally gives long arguments against a closer relationship between Ramapithecus and the Homo-lineage.

Today, Remane's most useful work may be his 209-page 'Zähne und Gebiß' (teeth and dentition) in Primatologia III/2, (1960b). It is probably the best introduction for a beginner in primate dental morphology and for the advanced beginner an always helpful reference. It deals with all genera and all important species. It includes much of his older publications, occasionally with more differentiated interpretations. Valuable is the chapter on deciduous teeth, which often give hints to the origin of structures on the permanent teeth. Unique are the crossreferences and cross-comparisons among all primate groups, enlightening and convincing are the argumentations for homology or analogy. Fine examples of a sovereign mind are many specific paragraphs, for example on the detailed comparisons between Pan and Homo, and the parallel development of bilophodont molars in primates (e.g. in Cebus, Cercopithecoidea, Symphalangus, Archaeolemuridae and in part Indriidae). Almost every page has at least one clear illustration; the great trends in the development of primate dentitions are summarised in the last chapter, with summaries on the specific families and genera (e.g. Hylobates, Gorilla, Pongo, Pan and Homo). 
Taxonomic Tapestries

\section{References}

Heydemann B. Zum Tode von Professor Dr.Dr.'.c. Adolf Remane (1977). FaunÖkol Mitt 5:85-91.

Hooijer, DA. 1951. Questions relating to a new large anthropoid ape from the Mio-Pliocene of the Siwaliks. Am J Phys Anthropol 9: 79-95.

Pilgrim GE, 1927. A Sivapithecus palate and other primate fossils from India. Memoirs of the Geological Survey of India (Palaeontologica Indica), NS(14):126.

Remane A. 1921. Beiträge zur Morphologie des Anthropoidengebisses. Archivf. Naturgeschichte, Abt. A 87:1-179.

Remane A. 1921. Zur Beurteilung der fossilen Anthropoiden. Centralblatt für Mineralogie, Geologie und Paläontologie 11:335-339.

Remane A. 1924a. Einige Bemerkungen über Prohylobates Tanyi R. Fourtau und Dryopithecus mogharensis R. Fourtau. Centralblatt f. Mineralogie, Geologie und Paläontologie 7:220-223.

Remane A. 1924b. Einige Bemerkungen zur Eckzahnfrage. Anthropolog Anz $1: 35-40$.

Remane A. 1927. Methoden zur Untersuchung der Primaten. Zur Meßtechnik der Primatenzähne. Handbuch biologischer Arbeitsmethoden. Abt. 7:609-635 Berlin, Wien.

Remane A. 1951. Die Entstehung der Bilophodontie bei den Milchmolaren oft phylogenet. Vorstufe Cercopithecidae. Anat Anz 98:161-165.

Remane A. 1952a. Methodische Probleme der Hominiden-Phylogenie I. Z Morph Anthrop 44:188-200.

Remane A. 1952b. Der vordere Prämolar (P3) von Australopithecus prometheus und die morphologische Stellung des Australopithecinengebisses. Z Morph Anthropol 43:288-310.

Remane A. 1953. Die primitivsten Menschenformen (Australopithecinae) und das Problem der tertiären Menschen. Schriften Naturwiss. Verein. Schleswig Holstein 29:3-10.

Remane A. 1954. Methodische Probleme der Hominiden Phylogenie II. Z Morph Anthrop 46:225-268. 
Remane A. 1955. Ist Oreopithecus ein Hominide? Abh. Math.-Naturw. Kl. Akad. Wiss. Mainz N.R. 12:469-497.

Remane A. 1956a. Paläontologie und Evolution der Primaten, besonders der Nicht-Hominoiden. Primatologia I(8). Basel, New York: S. Karger. pp. 267378.

Remane A. 1956b. Die Grundlagen des Natürlichen Systems, der Vergleichenden Anatomie und der Phylogenetik. 2. Aufl. Leipzig: Akademische Verlagsgesellschaft.

Remane A. 1960a. Die Stellung von Gigantopithecus. Anthropol Anz 24:146-159.

Remane A. 1960b. Zähne und Gebiss. Primatologia III(2). Basel, New York: S. Karger. pp. 637-846.

Remane A. 1961. Probleme der Systematik der Primaten. Z wiss Zool 165:1-34.

Remane A. 1962. Masse und Proportionen des Milchgebisses der Hominoidea. Bibl. Primatl. 1. Basel, New York: S. Karger. pp. 229-238.

Remane A. 1965. Die Geschichte der Menschenaffen. Hrsg. Gerhard Heberer. Menschliche Abstammungslehre. Stuttgart: Gustav Fischer Verlag. pp. 249309. 
This text is taken from Taxonomic Tapestries: The Threads of Evolutionary, Behavioural and Conservation Research, edited by Alison M Behie and Marc F Oxenham, published 2015 by ANU Press, The Australian National University, Canberra, Australia. 